\section{(6) OPEN ACCESS}

Department of Public Health, University of Otago, Wellington, New Zealand

\section{Correspondence to} Associate Professor Nick Wilson, Department of Public Health, Wellington School of Medicine, University of Otago, PO Box 7343, Wellington South, Wellington 6002 New Zealand;

Nick.wilson@otago.ac.nz

Received 18 September 2012 Revised 21 November 2012 Accepted 11 December 2012

To cite: Wilson $\mathrm{N}$ Thomson GW, Edwards R, et al. Tob Control 2013:22: i18-i21.

\title{
Potential advantages and disadvantages of an endgame strategy: a 'sinking lid' on tobacco supply
}

\author{
Nick Wilson, George W Thomson, Richard Edwards, Tony Blakely
}

\section{ABSTRACT \\ Background One possible supply-side strategy for the tobacco endgame is a government-mandated 'sinking lid' on tobacco supply (tradeable but decreasing quotas on sales or imports).}

Methods We considered literature on quota systems and from a tobacco endgame workshop at the University of Michigan.

Findings Likely strengths of the sinking lid strategy include: (1) that it can provide a clear timetable and an unambiguous signal of a tobacco end-date; (2) that supply reduction is likely to increase product price levels, and there is very strong evidence that increasing price is a highly effective tobacco control intervention. Its feasibility is also supported by the growing international experience with, and political acceptability of, using quota and auction systems in other domains (eg, greenhouse gases, other air pollutants and for fisheries). However, the main disadvantages of this strategy are probably the need for strong political will and high public support (to pass a new law), potential legal challenges by industry (eg, under trade agreements), and vulnerability to problems from illegal supplies of tobacco and from corruption.

Conclusions The sinking lid strategy is a plausible option that is worth considering when investigating possible tobacco endgame strategies, though it may be most applicable in well-organised jurisdictions with low $(<15 \%)$ adult smoking prevalence. This idea could benefit from further research, such as studies in virtual worlds, and real-world testing on small island jurisdictions, or closed systems, such as military bases.

\section{INTRODUCTION}

One possible supply-side strategy for the tobacco endgame at a jurisdiction-level is a 'sinking lid' on tobacco sales and/or imports. The basics of this idea have been described previously, ${ }^{1}$ but to summarise it could involve government-mandated set percentage point reductions in annual tobacco sales/import quotas from either: (1) the market share of each tobacco company at a baseline year; or (2) available tradeable quotas to either tobacco companies or to wholesalers (eg, that could be auctioned off regularly in declining amounts by a government agency). In the second option, the supply could even be controlled by a non-profit agency, as in the proposed regulated market model. ${ }^{2}$ Also, tobacco companies or wholesalers could be permitted to trade quotas on a government-regulated spot market. As supply became more constrained, tobacco price levels would be likely to rise, unless demand dropped sufficiently due to other tobacco control enhancements. Such higher price levels would reduce youth uptake of smoking, increase quitting and reduce relapse. As demonstrated through tobacco tax-driven price increases, increasing price is one of the most effective and most evidence-based mechanisms in tobacco control. ${ }^{3-5}$

The strategy would almost certainly be more successful if accompanied by intensified demand reduction measures, such as mass media campaigns to promote quitting (ideally funded by tobacco tax revenue and revenue from the auction sales of quota). Additional price regulation mechanisms (such as minimum price levels), may further prevent industry manipulation to blunt the price signal to smokers as supply declined. When the target prevalence level or end-date (eg, a target prevalence of $<1 \%$, or an end-date for legal tobacco sales) was approached, then all residual smokers could be switched to: pharmaceuticalgrade nicotine products, be permitted to grow their own tobacco, and/or be permitted to use controlled amounts of government-supplied tobacco/nicotine products via a 'smoker's licence'6).

Here we elaborate further on the potential advantages and disadvantages of the sinking lid strategy idea, and consider future research options. To inform this commentary, we considered literature on quota systems and one of us (NW) attended a June 2012 workshop on tobacco endgames at the University of Michigan (Ann Arbor, USA).

\section{DEVELOPMENTS RELEVANT TO THE SINKING LID STRATEGY}

There appear to be no further developments in advancing sinking lid-type strategies in the USA since Senator Michael Enzi proposed the 'Help End Addiction to Lethal Tobacco Habits Act' in 2007. However, in New Zealand, the sinking lid approach was recommended for further consideration by a Select Committee of Parliament, which had performed an inquiry into the tobacco industry in $2010 .{ }^{8}$ Nevertheless, progressing this approach has not been substantially picked up in the New Zealand Government's official response, ${ }^{9}$ and its subsequent tobacco control activities have been more focused on introducing multiyear series of annual tobacco tax increases. Although this country has announced a goal for a 'Smokefree Nation by 2025', there is still a marked lack of detail around definitions, plans and processes. ${ }^{1011}$

International experience with running various quota systems, often with large corporate players involved, provides some evidence that governments can run these successfully, and that they can have the desired impact. One example of a successful auction system is for sulphur dioxide emission 'allowances', and this system has been functioning in the USA since 1995 (it is currently run by the 
Environmental Protection Agency). ${ }^{12}$ Such an approach has been expanded to nitrogen oxides, and there is a grouping of 27 eastern US states which are part of a cap-and-trade system that is designed to reduce emissions of the target pollutants (sulphur dioxide and nitrogen oxides) by $70 \% .{ }^{13}$ Reviews of this US experience are favourable, ${ }^{14}{ }^{15}$ and there is also evidence for greenhouse gas emission reductions from the 'Regional Greenhouse Gas Initiative' in the USA. ${ }^{15}$ Perhaps because of this experience in the USA, some public health experts have recently advocated for a cap-and-trade system for controlling the excessive nutrients in the US food system (salt, sugar and unhealthy fats). ${ }^{16}$

By contrast with the US experience above, the international experience with quota systems and emissions trading systems for carbon appears more mixed. For example, the European Union's Emissions Trading Scheme has not performed as well as expected due to suboptimal design of the scheme (eg, excess distribution of free carbon allowances), and the impact of the global financial crisis on European economic activity. ${ }^{17}$ Nevertheless, the system has, without doubt, delivered carbon emission reductions, and it has been responsive to energy sector developments (eg, the German nuclear energy phase-down). ${ }^{17}$ Australia is now following suit, though its newly introduced pricing mechanism for carbon will not evolve into a cap-and-trade scheme until 2015. ${ }^{18}{ }^{19}$ China has announced seven emissions trading pilots, ${ }^{20}$ and there are emerging permit schemes in South Korea and Mexico. ${ }^{19}$

Even more common, internationally, are quota (or 'catch share') systems for fisheries, where total quotas can be reduced if necessary, and can be traded. One review has reported that 'implementation of catch shares halts, and even reverses, the global trend toward widespread collapse' of fisheries. ${ }^{21}$ More recent evidence from North American fisheries also suggests that these systems may generate some shift towards more ecological stewardship ${ }^{22}$ (ie, more sustainable long-term management). Nevertheless, it has been noted that such systems do not remove all incentives for poor stewardship, and that programme design is critical. ${ }^{22}$ Furthermore, some modelling work suggests that catch quota control when combined with a large closed area' to fishing can be the most effective system for maintaining both short and long-term economic performance'. ${ }^{23}$ In terms of a specific country example, the Organisation for Economic Co-operation and Development (OECD) has praised Iceland for the quality of its tradeable quota system that has helped ensure a sustainable (and profitable) fishery. ${ }^{24}$

Nevertheless, the examples described above still differ in critical aspects from a sinking lid of quotas on tobacco. Thus, while some societies might be described as suffering 'fossil fuel addiction', ${ }^{25}$ this is not the same as many citizens consuming a physiologically 'addictive' product daily (as it is with most smokers). Also these other quota systems do not usually aim for a rapid reduction in supply down to a very low level or with a complete sales end-date (eg, over 10-15 years as might be planned for tobacco).

\section{ADVANTAGES OF THE SINKING LID STRATEGY}

A likely strength of the sinking lid strategy is that it provides a clear timetable for policymakers and can include an unambiguous signal of the tobacco sales end-date. It is much more difficult to predict a target date for achievement of the endgame (eg, of $<1 \%$ smoking prevalence) solely using instruments such as ongoing tobacco tax rises. It is highly plausible that a clear timetable to an end-date would increase motivational tension in smokers and associated quitting behaviour (potentially via both planned and unplanned ${ }^{26}$ quit attempts). Such an approach could also facilitate more focused activity by the health sector around promoting and supporting smoking cessation.

Another likely advantage is that some of the mechanisms involved in the strategy are well understood. That is, the likely consequence of supply reduction, increased price (driven by tobacco tax increases), is a highly evidence-based tobacco control intervention in most countries. There are also the working analogies for how governments manage tradeable quota systems as discussed above. These aspects will provide some reassurance for policymakers concerned with achieving endgame success, and officials concerned with short-revenue streams. Indeed, by maintaining both tobacco taxation for the bulk of the revenue and also introducing revenue from auctioned quotas, a greater proportion of the tobacco price could potentially be shifted from tobacco industry profits into government revenue (especially if there was also a maximum pretax price that retailers and manufacturers could charge). ${ }^{27}$ In some jurisdictions, this could provide additional total revenue in the short term (for other tobacco control interventions or for health sector funding), until smoking prevalence falls appreciably, and then total revenue from this source declines. As with all tobacco endgame strategies, if governments wish to maintain constant revenue streams, then other types of taxes may need to be raised (eg, on pollutants such as carbon) as tobacco tax revenues start to decline.

As per most other endgame strategies in this supplement, this strategy is likely to be highly compatible with a wide suite of adjunct evidence-based tobacco control interventions (eg, expanded smokefree area laws, mass media campaigns, quitlines and other smoking cessation support). Indeed, for equity reasons (given that smokers are more likely to be people on relatively low incomes), it is optimal that strong adjunct interventions are part of a package so that demand is reduced in such a way that price does not become exorbitant in the short to medium term.

The sinking lid strategy would also be compatible with some other endgame strategies, such as a smoker's licence system ${ }^{6}$ (though for reasons of practicality, cost and political acceptability, this is perhaps best introduced at very low smoking prevalences). It could also be complemented with the strategy of phasing-down nicotine levels in all cigarettes on the market ${ }^{28}$ and of differential phase-outs for different types of tobacco products (depending on existing country-specific tobacco markets and views on harm reduction).

But there are trade-offs in terms of developing a strong and comprehensive endgame package versus a more simple approach that minimises demands on limited political capital and organisational capacity. Therefore, it may be more appropriate for small jurisdictions to run only with the sinking lid strategy, and accompany it with only traditional demand reduction interventions (smoking cessation support, etc).

\section{DISADVANTAGES OF THE SINKING LID STRATEGY Requires strong political leadership}

Probably the major disadvantage with the sinking lid strategy in democratic countries is that it faces the requirement of there being enough strong political leadership and public support to pass the necessary law. This political will would need to be particularly strong if the new law detailed the novel feature of including an endpoint, such as prohibiting legal tobacco sales and the start of any smoker's licence system. While public support has been described as a likely endgame requirement, ${ }^{29}$ the level of political leadership and continuing resolve may have to at least reach that recently shown by the Australian 
Government around introducing the world's first plain packaging law for tobacco products (which combines the removal of virtually all brand imagery with requiring larger pictorial health warnings). ${ }^{30}$ Low corruption levels would also be necessary to protect against pressure from the tobacco industry and its allies (retailers, advertisers and law firms, etc).

\section{Litigation risk}

The act of passing a law for a sinking lid strategy is far more likely to trigger tobacco company litigation against the government, compared with the use of incremental tobacco control strategies (eg, continuously raising tobacco tax). This litigation could be for loss of their investments ${ }^{31}$ (eg, as per legal action by the industry, using Australia's bilateral investment treaty with Hong Kong on the plain packaging issue ${ }^{32}$ ). However, it is uncertain if such litigation would succeed, and the risk of litigation might be reduced if the endpoint of the sinking lid strategy was just a low smoking prevalence $(e g,<1 \%)$ rather than a defined endpoint for legal tobacco sales. Also, while such litigation could increase costs to governments, such costs would almost certainly be trivial in relation to the health and social costs of continued tobacco sales.

\section{Illegal supply}

As supply was reduced, and as tobacco price levels increased, the problems of cross-border smuggling, thefts and illegal sales from duty-free purchases or local tobacco growers could rise (as they could with other price increase strategies). Such problems could definitely reduce the effectiveness of the sinking lid strategy and could undermine public and political support if the social costs associated with the criminality of supply were perceived to be too high. So the illegal supply problem may limit the viability of a sinking lid strategy to jurisdictions: with strong border controls; that are geographically isolated, such as islands; that have a well controlled (or no) tobacco growing sector; that have effective law enforcement; and have low corruption levels. Some of these issues can potentially be addressed through further investing in customs and police institutions, and removing tobacco growing within a country's own borders (eg, by a complete tobacco farming buyout programme). Other supportive measures to reduce these problems could include: eliminating duty-free allowances, prohibiting mail-order and internet sales on tobacco, and tighter controls on who is permitted to sell tobacco (eg, licensing of retailers).

\section{Industry counter-responses}

Beforehand, or once a sinking lid strategy was underway, tobacco companies could potentially disrupt it in various ways. For example, company collusion could disrupt any auction system for quota allocation, and companies might bribe officials to damage the auction system indirectly. This risk might suggest that the sinking lid strategy is probably more suited for nations with both low corruption levels and a strong civil service. But some risks could also be countered in advance, for instance, with governments having back-up tobacco supply arrangements with tobacco companies not currently supplying in the jurisdiction. Alternately, where the supply to wholesalers or retailers was only permitted to be from a non-profit agency, ${ }^{2}$ the risk of such responses may be reduced.

\section{POSSIBLE NEXT STEPS FOR FURTHER RESEARCH AND POLICY}

For the reasons given above, we acknowledge that the sinking lid strategy might ultimately be only an endgame strategy suited for well-organised jurisdictions with other favourable features, such as: relatively low smoking prevalence in adults (eg, under $15 \%$ ), and the other features referred to above (eg, minimal corruption). ${ }^{29}$ Nevertheless, settings using this strategy could achieve major population health gain, compared with the status quo in most countries of small incremental steps to gradually reduce smoking prevalence. Furthermore, we suspect that the world will probably need a range of different tobacco endgame strategies to cope with diverse country settings. Some of the research options that may advance understanding of a sinking lid strategy are as follows.

\section{Qualitative research}

Key informant interviews with the officials who run quota systems (eg, for air pollution and fisheries) could be conducted. Similarly, for key stakeholders such as senior politicians and senior officials, on their attitudes towards adopting a sinking lid strategy in their country. Particular contrasts could be drawn with key informants' views on the feasibility of alternative endgame strategies-particularly the most similar one of continuous large tobacco tax increases into the future.

\section{Reviewing existing quota systems}

There could be further review of the experience of how established quota systems work in practice, especially those where the quotas are reduced over time (eg, for carbon emissions, sulphur dioxide and nitrogen dioxide emissions and quotas for endangered fish species). Australia's new carbon pricing mechanism provides a number of state-of-the-art design features ${ }^{19}$ that could be worthy of further examination.

\section{Experiments in virtual worlds}

'Virtual worlds' are used to study economic behaviour, such as the nature of exchange ${ }^{33}$ and purchasing behaviour in virtual supermarkets. ${ }^{34}$ Such an approach could be used for endgame experiments whereby the full tobacco endgame in a jurisdiction is simulated (eg, at a scale of 1 day equals 1 year). A range of hired business people could function as simulated 'tobacco company executives' trying to maximise profits and outmanoeuvre the 'regulators' (from treasury and health ministries) who are running the auctions and other components of the sinking lid strategy.

\section{Real-world testing}

The sinking lid strategy could be applied in a relatively closed system, such as on a military base (especially if on an island), or for the occupants of a large naval vessel such as an aircraft carrier. A small island jurisdiction is a more real-world option, particularly an island which is, or is part of, an OECD country with a social science research base (eg, Iceland). To kick-start the process, a philanthropic organisation could perhaps offer a multimillion dollar 'tobacco endgame prize' for any island jurisdiction that wishes to operationalise the sinking lid strategy and permit appropriate validation by researchers, and with appropriate ethical oversight (eg, such prizes for other topic areas have been put forward by the X Prize Foundation, (X Prize Foundation, Playa Visa, California, USA, http://www.xprize.org/)). Technical assistance 'when needed' from other countries could be permitted, as has previously been suggested for advancing tobacco control on the small Pacific island nation of Niue. ${ }^{35}$ Nevertheless, remote island jurisdictions without airports (eg, Tokelau) may be even more suitable, as then the smuggling risk is reduced accordingly. 


\section{CONCLUSIONS}

The sinking lid strategy needs to be considered as an endgame strategy even though it might only be applicable in certain types of jurisdictions. This idea could benefit from further research to access its feasibility (eg, via key informant interviews). Evaluation in simulated online worlds may be worthwhile, along with real-world testing that starts with small island jurisdictions, or closed systems such as military bases.

Acknowledgements The authors thank the organisers of the workshop at the University of Michigan School of Public Health (Ann Arbor, USA) and the workshop funders (see below).

Contributors All authors contributed to the overall design of the article. NW attended the University of Michigan workshop and relevant new literature was identified by NW, GT and RE. The manuscript was drafted by NW and was critically revised by all other authors, who also approved the final version. NW is the guarantor.

Funding The Robert Wood Johnson Foundation and American Legacy Foundation funded the workshop. Nick Wilson and Tony Blakely are also supported by the BODE programme which is modelling tobacco endgame strategies and receives funding support from the Health Research Council of New Zealand (Project number 10/248).

Competing interests None.

Provenance and peer review Not commissioned; externally peer reviewed.

Open Access This is an Open Access article distributed in accordance with the Creative Commons Attribution Non Commercial (CC BY-NC 3.0) license, which permits others to distribute, remix, adapt, build upon this work non-commercially, and license their derivative works on different terms, provided the original work is properly cited and the use is non-commercial. See: http://creativecommons.org/ licenses/by-nc/3.0/

\section{REFERENCES}

1 Thomson G, Wilson N, Blakely T, Edwards R. Ending appreciable tobacco use in a nation: using a sinking lid on supply. Tob Control 2010;19:431-5.

2 Borland R. A strategy for controlling the marketing of tobacco products: a regulated market model. Tob Control 2003;12:374-82.

3 Chaloupka FJ, Straif K, Leon ME. Effectiveness of tax and price policies in tobacco control. Tob Control 2011;20:235-8.

4 Chaloupka FJ, Yurekli A, Fong GT. Tobacco taxes as a tobacco control strategy. Tob Control 2012:21:172-80.

5 International Agency for Research on Cancer (IARC). Effectiveness of tax and price policies for tobacco control. IARC Handbooks of Cancer Prevention in Tobacco Control. Volume 14. Lyon: IARC, 2011.

6 Chapman S. The case for a smoker's license. PLoS Med 2012:9:e1001342.

7 Enzi M. Help End Addiction to Lethal Tobacco Habits Act. S. 1834. US Senate. 2007.

8 Blakely T, Thomson G, Wilson N, et al. The Maori Affairs Select Committee Inquiry and the road to a smokefree Aotearoa. N Z Med I 2010;123:7-17.

9 NZ Parliament. Government Response to the Report of the Māori Affairs Committee on its Inquiry into the tobacco industry in Aotearoa and the consequences of tobacco use for Māori (Final Response). Wellington: New Zealand (NZ) Parliament, 2011. http:/l www.parliament.nz/NR/rdonlyres/3AAA09C2-AD68-4253-85AE-BCE90128C1A0/ 187795/DBHOH_PAP 21175 GovernmentFinalResponsetoReportoft.pdf (accessed 21 Nov 2012).

10 Wilson N, Blakely T, Hoek J, et al. The Government's goal for a smokefree New Zealand by 2025: more decisions, and more detail, are urgently needed. N Z Med J 2011:124:111-13.
11 Wilson N, Hoek J, Thomson G, et al. Fifty years since the Royal College Report: more action needed to achieve the 'smokefree New Zealand by $2025^{\prime}$ goal. $N Z$ Med J 2012:125:109-12.

12 US Environmental Protection Agency. Acid Rain Program SO2 Allowances Fact Sheet. http://www.epa.gov/airmarkt/trading/factsheet.html (accessed 21 Jul 2012).

13 US Environmental Protection Agency. Clean Air Interstate Rule (CAIR). http://www. epa.gov/airmarkt/progsregs/cair/index.html (accessed 21 Jul 2012).

14 Chestnut L, Mills D. A fresh look at the benefits and costs of the US acid rain program. J Environ Manage 2005;77:252-266.

15 Tietenberg T. Cap-and-trade: the evolution of an economic idea. Agric Resour Econ Rev 2010;39:359-367. http://ageconsearch.umn.edu/bitstream/95836/2/tietenberg \%20-\%20current.pdf (accessed 21 Jul 2012).

16 Lewis KH, Rosenthal MB. Individual responsibility or a policy solution-cap and trade for the U.S. diet? N Engl J Med 2011:365:1561-3.

17 van Renssen S. Saving EU climate policy. Nature Clim Change 2012;2:392-3.

18 Keenan R, Caripis L, Foerster A, et al. Science and the governance of Australia's climate regime. Nature Clim Change 2012;2:477-478.

19 Jotzo F. Australia's carbon price. Nature Clim Change 2012;2:475-476.

20 Yu G, Elsworth R. Turning the Tanker: China's Changing Economic Imperatives and its Tentative Look to Emissions Trading: Sandbag. 2012. http://www.sandbag.org. uk/site_media/pdfs/reports/Sandbag_Turning_the_Tanker_Final.pdf (accessed 21 Jul 2012)

21 Costello C, Gaines SD, Lynham J. Can catch shares prevent fisheries collapse? Science 2008;321:1678-81.

22 Essington TE. Ecological indicators display reduced variation in North American catch share fisheries. Proc Natl Acad Sci USA 2010;107:754-9.

23 Stefansson G, Rosenberg AA. Combining control measures for more effective management of fisheries under uncertainty: quotas, effort limitation and protected areas. Philos Trans R Soc Lond B Biol Sci 2005;360:133-46.

24 Haraldsson G, Carey D. Ensuring a Sustainable and Efficient Fishery in Iceland IOECD Economics Department Working Papers No. 891]. Paris: OECD, 2011. http://www. oecd-library.org/economics/ensuring-a-sustainable-and-efficient-fishery-iniceland_5kg566jfrpzr-en (accessed 21 Jul 2012).

25 Perera FP. Children are likely to suffer most from our fossil fuel addiction. Environ Health Perspect 2008;116:987-90.

26 Ferguson SG, Shiffman S, Gitchell JG, et al. Unplanned quit attempts-results from a U.S. sample of smokers and ex-smokers. Nicotine Tob Res 2009;11:827-32.

27 Gilmore AB, Branston JR, Sweanor D. The case for OFSMOKE: how tobacco price regulation is needed to promote the health of markets, government revenue and the public. Tob Control 2010;19:423-30.

28 Benowitz N. Nicotine reduction [Endgame proposal presentation]. Workshop on Endgame Strategies in Tobacco Control. Ann Arbor: University of Michigan School of Public Health, 2012:19-21.

29 Thomson G, Edwards R, Wilson N, Blakely T. What are the elements of the tobacco endgame? Tob Control 2012:21:293-295.

30 Chapman S. Legal action by Big Tobacco against the Australian government's plain packaging law. Tob Control 2012;21:80-1.

31 Kelsey J. International trade law and tobacco control. Auckland: University of Auckland, 2012. http://www.turanga.org.nz/sites/turanga.org.nz/files/Kelsey\% 20Trade\%20Law\%20Tobacco\%20Control\%20Report.pdf (accessed 21 Nov 2012).

32 Sweet M. Tobacco companies launch legal action against plain packaging. BMJ 2011:343:d4270.

33 Kaplan HS, Schniter E, Smith VL, Wilson BJ. Risk and the evolution of human exchange. Proc Biol Sci 2012;279:2930-5.

34 Waterlander WE, Scarpa M, Lentz D, Steenhuis IH. The virtual supermarket: an innovative research tool to study consumer food purchasing behaviour. BMC Public Health 2011;11:589.

35 Hale M, McCool J, Bullen C, Nosa V. Views from a small Pacific island: prospects for tobacco control on Niue. Health Promot Pract 2012:13:404-11. 